\title{
Anatomía de la semilla de Chenopodium berlandieri ssp. nuttalliae (Chenopodiaceae) "huauzontle" 1
}

\author{
AIDA CARRILLO OCAMPO ${ }^{2,3}$ y E.MARK ENGLEMAN ${ }^{2}$
}

RESUMEN. La semilla del huauzontle (Chenopodium berlandieri ssp. nuttalliae) se estudió con microscopía fotónica y con microscopía electrónica de barrido. Se encontró que cuando el tegumento externo se eleva alrededor del óvulo joven, en lugar de cubrir al tegumento interno y la nucela, crece en sentido inverso y rodea parcialmente al funículo. Cuando el pericarpo se retira, el color de la semilla es pajizo, ya que solamente el tegmen cubre la semilla madura. La cálaza aquí tiene forma semejante a un cono truncado, con una base elíptica hacia la nucela; en esta zona de contacto entre la cálaza y la nucela, se deposita una cutícula que rodea algunas células en forma de red tridimensional. Esta red cuticular-calazal está en contacto con una cutícula nucelar lisa que forma parte de la cubierta seminal. La inversión del tegumento interno podría representar una mutación seleccionada durante la domesticación.

ABSTRACT. The seed of huauzontle (Chenopodium berlandieri ssp. nuttalliae) was studied by light microscopy and scanning electron microscopy. When the outer integument arises around the young ovule, instead of covering the inner integument and the nucellus, it grows backwards and partially surrounds the funiculus. When the pericarp is removed from the mature fruit, the seed is straw colored, because only the tegmen covers the seed. The chalaza of this seed has the form of a truncate cone, with the elliptical base towards the nucellus. In this zone of contact between the chalaza and the nucellus, a cuticle is deposited that surrounds some cells and makes a three dimensional network. This chalazal network is in contact with a smooth nucellar cuticle that forms part of the seed coat. The inversion of the inner integument could represent a selected mutation during the process of domestication.

\footnotetext{
${ }^{1}$ Este trabajo es parte de la tesis de maestría de la primera autora, presentada en abril de 1992, en el Centro de Botánica, Colegio de Postgraduados.

${ }^{2}$ Centro de Botánica, Colegio de Postgraduados, 56230 Chapingo, Edo. de México.

${ }^{3}$ Dirección actual: Area de Biología, Preparatoria Agricola, Universidad Autónoma Chapingo, 56230 Chapingo, Edo. de México.
} 
El huauzontle es una hierba anual, erecta, e inodora. Sus flores pediceladas se agrupan en panículas ovoides de glomérulos; son hermafroditas y unisexuales, en su mayoría femeninas, en la misma inflorescencia. El huauzontle pertenece a la subsección Cellulata del género Chenopodium 'Aellen y Just, 1943; Wilson y Heiser, 1979). La ubicación del huauzontle como una subespecie de Chenopodium berlandieri, todavía no es ampliamente aceptada. Para los propósitos del presente trabajo se sigue el antecedente de Wilson y Heiser (1979) porque ellos han estudiado la taxonomía de esta especie en detalle.

Con base en material arqueológico, Smith (1989) afirma que la reducción en el grosor de la cubierta seminal es una tendencia común, favorecida durante el proceso de domesticación de Chenopodium. En el presente trabajo, efectivamente se encontró que la semilla del huauzontle tiene el tegumento externo sumamente reducido, pero no por disminución en grosor, sino por reducción en su extensión. Este desarrollo aparentemente no ha sido descrito en alguna otra planta.

El objetivo del estudio es aportar información acerca de la estructura de la semilla de Chenopodium berlandieri ssp. nuttalliae (huauzontle), con énfasis en la estructura de la cubierta seminal y la cálaza.

\section{MATERIALES Y MÉTODOS}

El 27 de julio de 1987 se sembró huauzontle en una parcela de $2 \mathrm{~m}^{2}$ ubicada en Chapingo, Méx. Las semillas procedían de La Purificación, Estado de México. También se obtuvo material de una parcela cuyas semillas procedian de Toluca, Estado de México (variedad Santa Elena Siete, del Area de Hortalizas, Departamento de Fitotecnia, Universidad Autónoma Chapingo). Se colectaron óvulos, semillas y frutos en diferentes estados de desarrollo. El material procedente de La Purificación se fijó en Craf III (Solución A y Solución B mezcladas en partes iguales; Solución A: formalina (formaldehido al 35-40\%) al 23\%; Solución B: trióxido de cromo al 0.6\% + ácido acético al 4\%). El cultivar Santa Elena Siete se fijó en FAA (formalina al 10\%+ etanol al 48\%+ ácido acético al 5\% + agua al 37\%). Las muestras se lavaron y se pasaron a GAA (glicerol al $25 \%$, alcohol al $50 \%$ y agua al $25 \%$ ). Se siguió la técnica usual para inclusión de tejidos en parafina. Los cortes se hicieron a 8 micrómetros de grosor y se tiñeron con: safranina-verde fijo, rojo $\mathrm{O}$ de aceite o APS azul negro de naftol.

Safranina: safranina $\mathrm{O}$ saturado (menor de $0.05 \%+2 \%$ cloruro de sodio en agua)

Verde fijo: verde fijo FCF (o verde rápido) al $0.12 \%$ en 2-propanol (alcohol isopropílico) al 95\%.

Rojo $\mathrm{O}$ de aceite: rojo $\mathrm{O}$ de aceite saturado (menor de $0.05 \%$ ) +1 -butanol al $25 \%+$ etilenglicol al $75 \%$. 
APS: ácido peryódico al $0.5 \%$ luego, reactivo de Schiff $(0.1 \mathrm{~g}$ fuchsina básica disuelta en $2.0 \mathrm{ml}$ alcohol $+2.0 \mathrm{~g}$ bisulfito de sodio $\left(\mathrm{NaHSO}_{3}\right)$ disuelto en $100 \mathrm{ml} \mathrm{de}$ agua destılada $+4.0 \mathrm{~g}$ de ácido cítrico). Después de ser teñidos con APS, los cortes se lavaron con alcohol al $50 \%$, y se tiñeron con azul negro de naftol (negro B de naftol al $1 \%$ en alcohol al $50 \%$, técnica modificada de Fisher (1968).

Para separar la cutícula nucelar se seleccionaron algunas semillas maduras bajo el microscopio de disección (MD), y se montaron sobre palitos de madera con cianoacrilato (Kola Loka) para realizar cortes a mano. Los cortes se colocaron directamente en ácido sulfúrico al $60 \%$ + permanganato de potasio (hasta que la solución viró a castaño) + agua oxigenada (hasta que la solución se hizo incolora), por $48 \mathrm{~h}$. Las cutículas separadas se lavaron, se colocaron en alcohol al $50 \%$ y $60 \%$ y se tiñeron con rojo $\mathrm{O}$ de aceite. Para microscopía electrónica de barrido (MEB), se emplearon óvulos, semillas y frutos completos y disectados bajo el MD. Una parte de este material se incluyó en parafina para cortes con microtomo. Todas las muestras se deshidrataron hasta alcohol absoluto y se secaron por punto crítico. Se montaron sobre portaobjetos de metal cilíndricos, se llevaron al Laboratorio de Microscopía Electrónica del Colegio de Postgraduados. Se colocaron en una ionizadora a 1200 voltios, se recubrieron con $7 \mathrm{~nm}$ de oro y se registraron fotográficamente con película Verichrome Pan formato 120.

El largo, ancho y grosor de la semilla se obtuvieron a partir de una hilera de diez semillas, de la variedad Santa Elena Siete y otra de La Purificación, montadas en plastilina (arcilla con aceite). Cada hilera se midió con una reglilla graduada en décimas de milímetro. Para la obtención del peso aproximado de cada semilla, se seleccionaron 100 semillas de cada variedad, las cuales se pesaron en una balanza analítica. El volumen aproximado de la semilla se obtuvo mediante la fórmula del elipsoide: $V=(4 / 3) \pi a b c$, en donde a, b y c, son los semidiámetros de la semilla (las mitades de las medidas de largo, ancho y grosor). El volumen aproximado del embrión se obtuvo mediante la fórmula del cilindro: $V=\pi r^{2} h$, en donde $r$ es el radio y $h$ es la altura o longitud total del embrión. Otras medidas como el grosor de los tegumentos, de la cutícula nucelar, etc., se obtuvieron de cortes mediante un micrómetro ocular calibrado.

\section{RESULTADOS}

Descripción general del fruto y la semilla. La semilla madura del huauzontle yace horizontal en el fruto, y está íntimamente adherida al pericarpo. La cara superior del fruto es casi plana, con una pequeña cicatriz estigmática o restos del estigma (fig. 1). La cara inferior es convexa, se hace cónica hacia el canto y contiene en el centro la cicatriz del desprendimiento del receptáculo floral. La semilla liberada del 


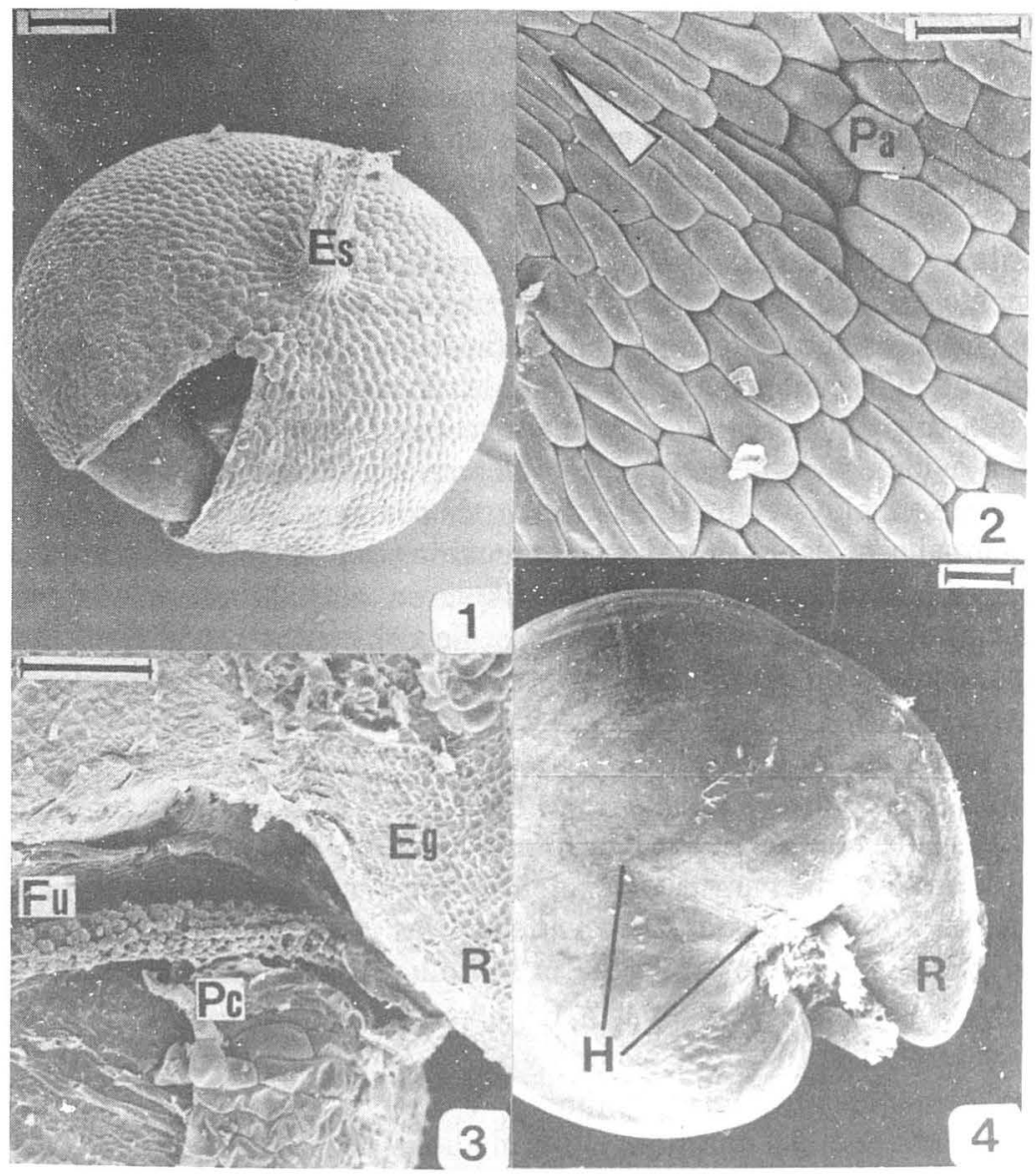

Fig. 1. Fruto semi-maduro, papiloso. La zona de la radícula se ve a través de la parte rota del pericarpio. Es=estigma colapsado. Microscopía electrónica de barrido $(\mathrm{MEB})$. Barra $=2(0) \mu \mathrm{m}$.

Fig. 2. Acercamiento de la superficie del pericarpo semi-maduro. Nótese como algunas papilas (Pa) se alargan hacia el estigma (flecha). (MEB). Barra $=60 \mu \mathrm{m}$.

Fig. 3. Semila madura, pero no seca. Las paredes anticlinales de las células del endotegmen (Eg) forman finas costillas en forma de red (superficie finamente alveolada). Co = región de los cotiledones, $\mathrm{Fu}=$ funículo, $\mathrm{Pc}=$ pericarpo, $\mathrm{R}=$ región de la radícula . $(\mathrm{MEB})$. Barra $=200 \mu \mathrm{m}$.

Fig. 4. Semilla madura sin el pericarpo y sin la cubierta. Observe la radícula $(R)$ muy prominente, y la formación de dos lóbulos del perispermo debido a la huella del funículo (H) sobre la superficie de la semilla. $(\mathrm{MEB})$. Barra $=200 \mu \mathrm{m}$. 
pericarpo tiene la radícula muy prominente (fig. 3). Sobre su cara inferior se encuentra un pequeño surco radial donde anida el funículo (fig. 4). La zona hilar está ocupada en parte por una prominencia de color castaño obscuro. El hilo es una zona pequeña donde el funículo se une a la prominencia (fig. 5). En las semillas jóvenes y semi-maduras el micrópilo se proyecta como un pezón curvado hacia la zona hilar (fig. 7). A medida que la semilla madura, el micrópilo se colapsa y obscurece (fig. 8).

Al MEB la superficie del pericarpo inmaduro es papilosa (figs. 1, 2). Las papilas se alargan en sentido radial hacia el estigma (fig. 2) y hacia el receptáculo floral. En el fruto maduro las papilas se colapsan (fig. 18). El color del pericarpo varía, incluso en un mismo individuo, entre amarillo, castaño y rojizo. El color de la semilla es pajizo. La superficie de la semilla adulta está adornada por finas costillas en forma de red (fig. 4). La semilla madura, con o sin el pericarpo, mide $1.65 \mathrm{~mm}$ de ancho por $1.75 \mathrm{~mm}$ de largo por $0.85 \mathrm{~mm}$ de grosor. Tiene un peso de alrededor de $2 \mathrm{mg}$ y su volumen aproximado es de $1.3 \mathrm{~mm}^{3}$. El volumen del embrión es más o menos de $0.35 \mathrm{~mm}^{3}$.

Las cubiertas de la semilla. Las cubiertas de la semilla joven del huauzontle presentan una prominencia carnosa, formada por el labio o tegumento externo, la cálaza y el hilo. La disposición de estas partes se representa en la figura 5. La prominencia pierde turgencia a medida que la semilla madura (figs. 7, 9, 18). Por su forma y posición desusual hemos aplicado el nombre de "labio" a este tegumento.

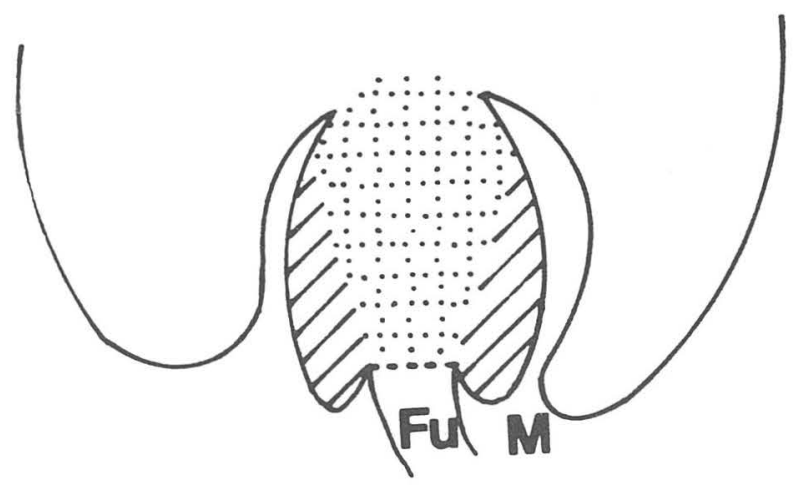

Fig. 5. Esquema de un corte mediano de semilla jóven, mostrando el arreglo de las partes de la prominencia. La zona sombreada con líneas representa el labio o tegumento externo; la zona punteada es la cálaza con forma de cono truncado. La línea interrumpida representa el hilo. $\mathrm{M}=$ zona del micrópilo, $\mathrm{Fu}=$ funículo. 
BOLETÍN DE LA SOCIEDAD BOTÁNICA DE MÉXICO, Núm. 54, 1994

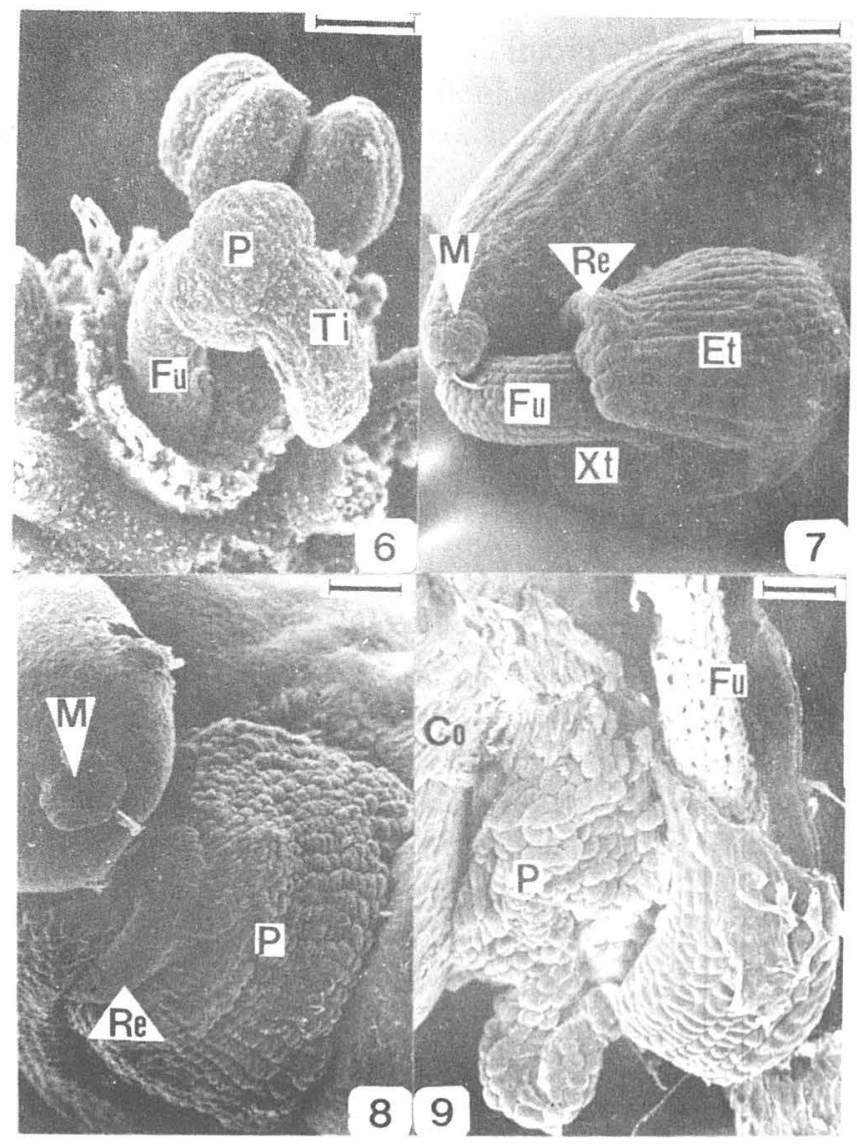

Fig. 6. Ovulo cubierto por el tegumento interno (Ti), mientras que el labio, o tegumento externo, crece hacia el funículo $(\mathrm{Fu})$ y lo envuelve parcialmente. $\mathrm{P}=$ prominencia. (MEB). Barra $=60 \mu \mathrm{m}$.

Fig. 7. Semilla joven, mostrando la prominencia (P) carnosa con la hendidura en forma de $\mathrm{V}$, hacia el lado de los cotiledones (Co). Una parte de la exotesta (Xt) queda en contacto con el funículo $(\mathrm{Fu})$ y otra parte es expuesta en el reborde (Re), en tanto que la endotesta (Et) queda por fuera. Observe el micrópilo (M) en forma de pezón. Fu = funículo. (MEB). Barra $=60 \mu \mathrm{m}$.

Fig. 8. Semilla semi-madura con la prominencia $(P)$ y el reborde $(R e)$ reducidos por el colapso de sus células y por el mayor crecimiento del resto de la semilla. En esta etapa también el micrópilo (M) está colapsado. (MEB). Barra $=60 \mu \mathrm{m}$.

Fig. 9. Zona hilar de la semilla madura, pero no seca. Nótese el mayor colapso de la prominencia (P) que en la etapa anterior, y su apariencia irregular. $\mathrm{Fu}=$ funículo, $\mathrm{Co}=$ zona de los cotiledones. (MEB). Barra $=60 \mu \mathrm{m}$. 


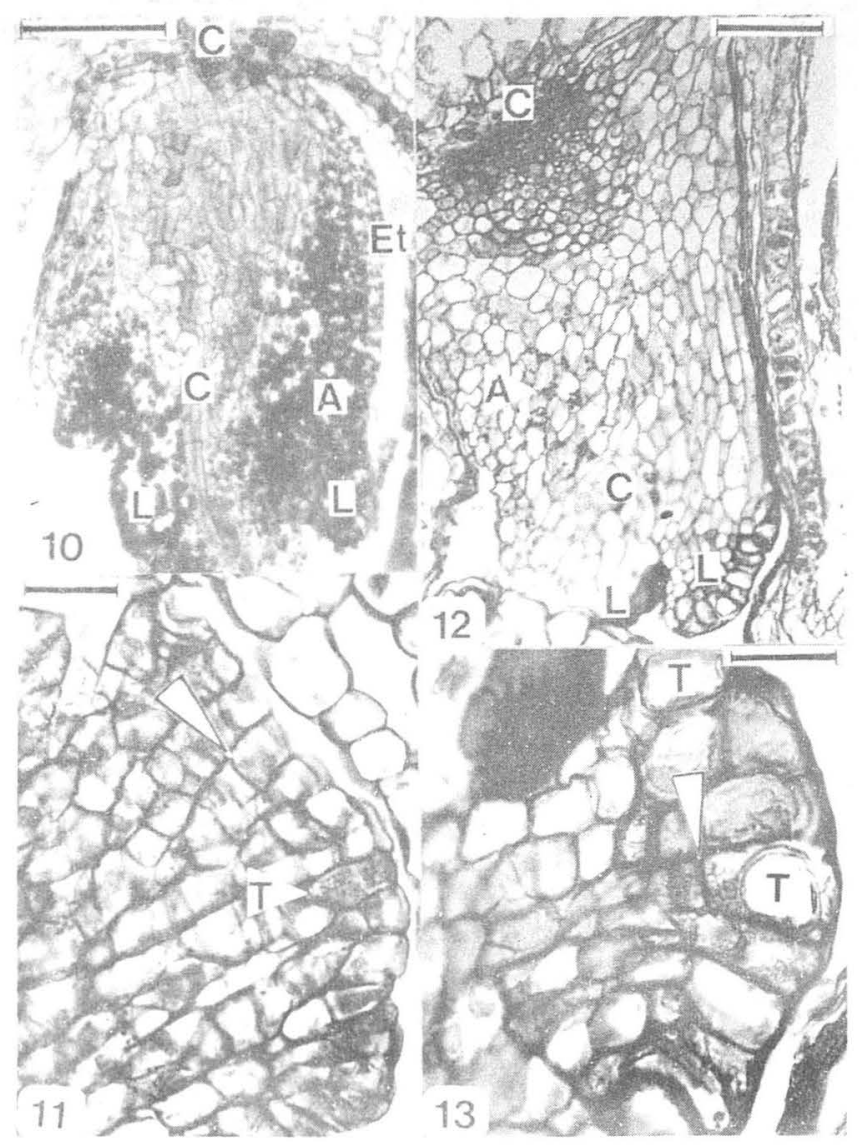

Fig. 10. Labio (L) y cálaza (C) en corte mediano de la semilla joven, teñido con APS. Nótese la gran cantidad de almidón (A), en el labio. Las células de la endotesta (Et) cubren el labio externamente. Esta fotografía es comparable al dibujo de la figura 5. Microscopio compuesto (MC). Barra $=60 \mu \mathrm{m}$.

Fig. 11. Exotesta en corte mediano del labio en la semilla joven, teñido con APS. Observe una división periclinal (flecha), y taninos condensados (T) en el lumen de algunas células. (MC). Barra $=20 \mu \mathrm{m}$.

Fig. 12. Labio (L) y cálaza (C) en corte mediano de la semilla semi-madura, teñido con APS. Nótese que la cantidad de almidón (A) ha disminuído con respecto a la figura 10. (MC). Barra $=60 \mu \mathrm{m}$.

Fig. 13. Exotesta en corte mediano del labio en semilla semi-madura, teñido con APS. Observe una división periclinal (flecha) y la mayor cantidad de taninos condensados (T) que en la figura 11. Note que la pared periclinal externa está un poco más engrosada que las anticlinales. (MC). Barra $=20 \mu \mathrm{m}$. 


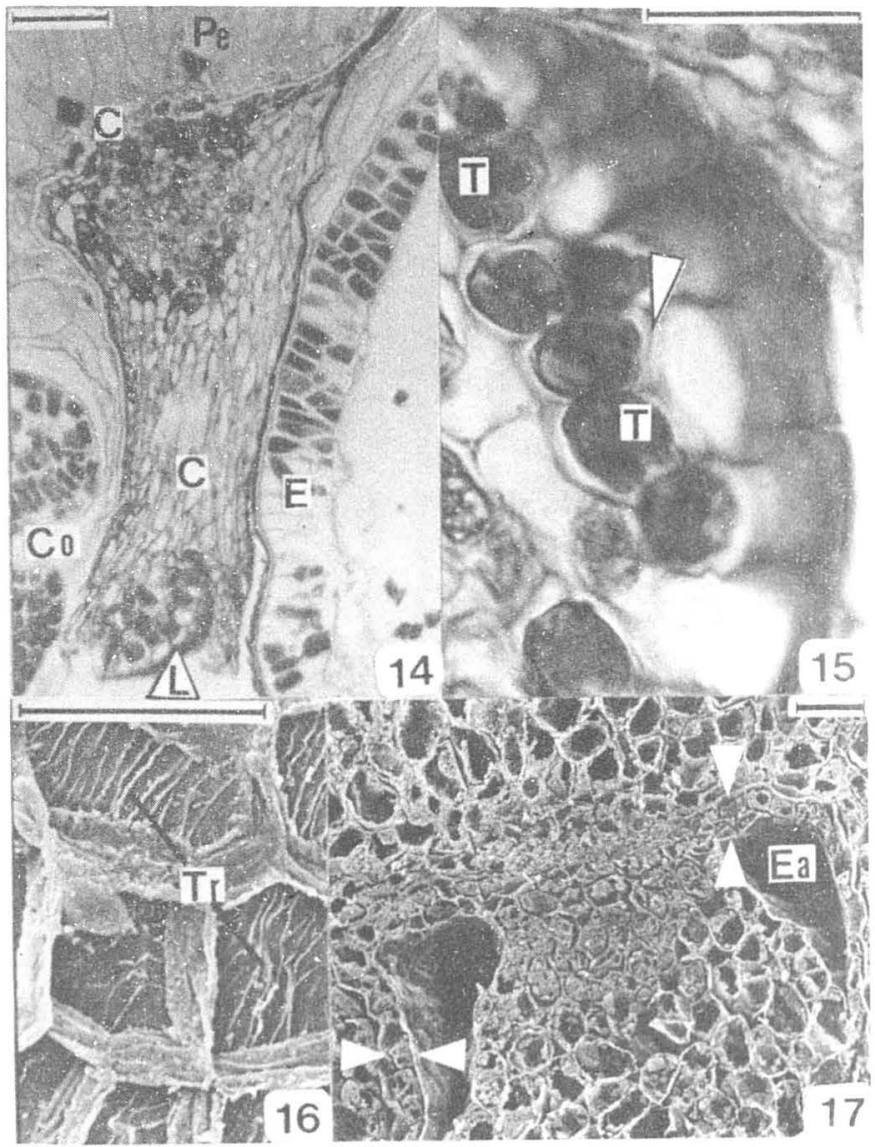

Fig. 14. Labio (L) y cálaza (C) en corte mediano de la semilla madura, pero no seca, teñido con Safraninaverde fijo. Las células del labio y la cálaza están más colapsadas que en la figura 12. $\mathrm{Co}=$ cotiledones, $\mathrm{E}=$ endospermo, $\mathrm{Pe}=$ perispermo. $(\mathrm{MC}) . \mathrm{Barra}=60 \mu \mathrm{m}$.

Fig. 15. Exotesta en corte mediano del labio en la semilla madura, pero no seca, teñido con safraninaverde fijo. Observe una división periclinal (flecha). Los taninos (T) llenan ahora el lumen celular. La pared periclinal externa se ha engrosado más que en la figura 13, y es ligeramente convexa. (MC). Barra $=20 \mu \mathrm{m}$.

Fig. 16. Vista superficial del endotegmen de semilla madura. Observe las estrías (Tr), paralelas y sesgadas sobre la pared periclinal interna. (MEB). Barra $=20 \mu \mathrm{m}$.

Fig. 17. Corte mediano de la zona hilar de la semilla joven. La cubierta consta solamente del endotegmen ( $\$$ ). Observe el espacio de aire (Ea) que queda entre el tegumento interno y el externo. Se ven todavía dos células intactas del exotegmen ( $\nabla$ ). (MEB). Barra $=20 \mu \mathrm{m}$. 


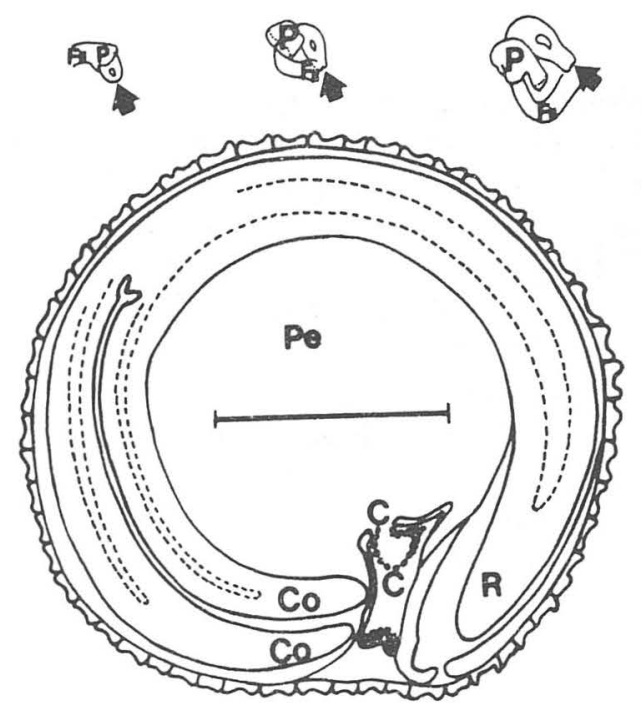

Fig. 18. Dibujos de dos óvulos, una semilla joven y una semilla madura a la misma escala. Nótese el aumento en tamaño y en la curvatura del óvulo. En los óvulos y la semilla jóven la prominencia $(\mathrm{P})$ tiene es muy notable, en tanto que en la semilla madura su tamaño relativo se reduce. $\mathrm{C}=$ cálaza, $\mathrm{Co}=$ cotiledones, flecha $=$ micrópilo, $\mathrm{Pe}=$ perispermo, $\mathrm{R}=$ radícula. $\mathrm{Barra}=600 \mu \mathrm{m}$.

El tegumento externo (labio) no crece hacia el micrópilo. En lugar de envolver la nucela, crece hacia el funículo, y lo rodea parcialmente cerca de la cálaza (fig. 6). Este crecimiento inverso provoca que la exotesta quede interna (junto al funículo) y la endotesta externa (fig. 7). Visto al MEB, el labio muestra en algunas semillas jóvenes un reborde en su parte distal y una hendidura en forma de $\mathrm{V}$ hacia los cotiledones (fig. 7). Al microscopio fotónico (MF) en cortes teñidos con APS, se detectó que en esta etapa las células del labio son muy ricas en almidón (fig. 10). En la semilla joven muchas células de la exotesta están en hileras de 23 (figs. 11, 13). Todas las paredes de la exo y endotesta son delgadas en esta etapa (fig. 11). A medida que la semilla crece, el labio y la cálaza reducen su tamaño relativo y la cantidad de almidón disminuye (fig. 12). En cortes de semilla semi-madura, la pared periclinal externa de la exotesta mide $2 \mu \mathrm{m}$ de grosor y tiñe de rosa con APS. Las anticlinales miden $1 \mu \mathrm{m}$. Hay taninos en el lumen (fig. 13). Al MEB el labio en la semilla madura es una estructura de forma irregular, con muchos plegamientos y ondulaciones (fig. 9). En cortes de la semilla madura, el lumen de algunas células de la exotesta contiene 
abundantes taninos pardos, los cuales forman grandes conglomerados de hasta $20 \mu \mathrm{m}$ de diámetro (fig. 15). Las células de la exotesta que se ubican en el borde del labio, se distinguen claramente, por ser cuboides y un poco alargadas en sentido anticlinal, y sobre todo, por tener la pared periclinal externa ligeramente convexa y con un grosor de hasta $10 \mu \mathrm{m}$ (fig. 15). Las paredes anticlinales son delgadas excepto donde se unen a la periclinal externa. Con tinción de safranina-verde fijo la pared periclinal externa presenta dos capas: una externa roja y otra interna azul-verde. Con tinción de APS, la capa externa de la pared no se tiñe y la interna se tiñe de rosa. La pared no se tiñe con rojo $\mathrm{O}$ de aceite. La pared sin tinción es de color pardo claro, sin estalactitas notables.

En el óvulo y la semilla muy joven, un espacio queda entre el tegumento externo y el tegumento interno, a nivel de la cálaza (fig. 17). En esta etapa el tegumento interno está formado por dos estratos, cada uno de $5 \mu \mathrm{m}$ de grosor, el exotegmen y el endotegmen, que inicialmente son muy semejantes (fig. 19).

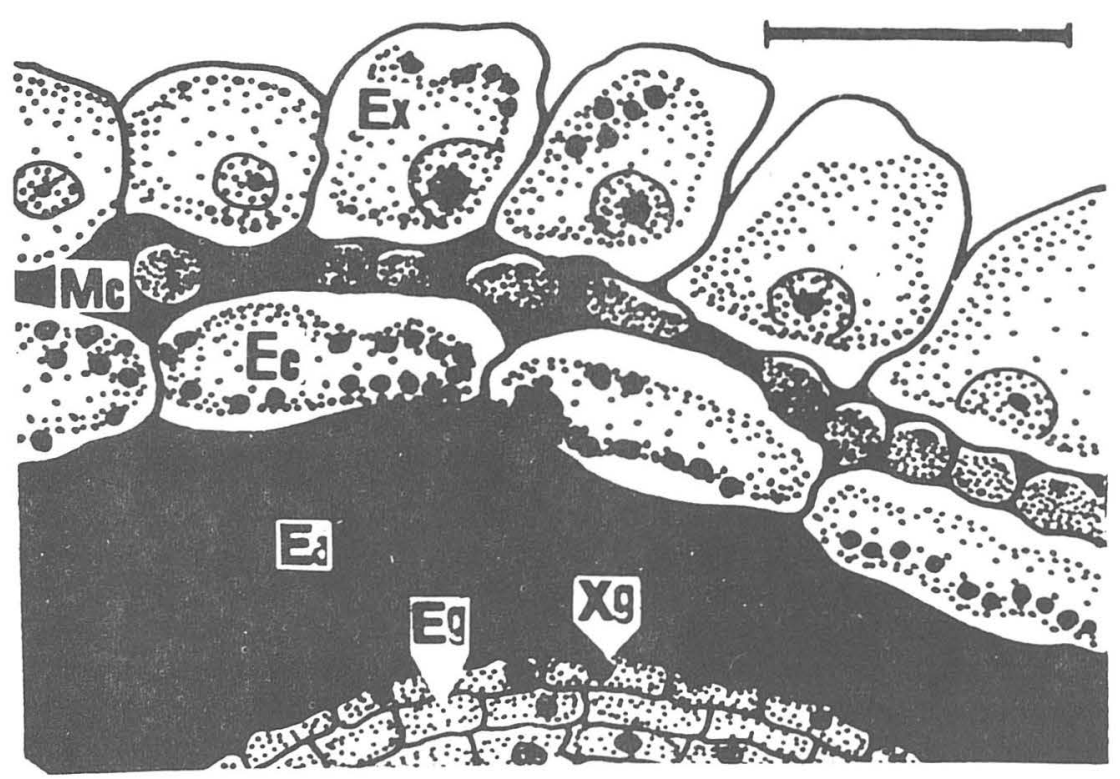

Fig. 19. Corte transversal de fruto muy joven. Pericarpo formado por tres estratos: exocarpo (Ex), mesocarpo (Mc) y endocarpo (Ec). Note la ausencia de tejido vascular y estomas. Cubierta de la semilla formada por exotegmen $(\mathrm{Xg})$ y endotegmen $(\mathrm{Eg})$ muy similares. Los espacios intercelulares se dibujaron negros. $\mathrm{Ea}=$ espacio de aire. Barra $=20 \mu \mathrm{m}$. 


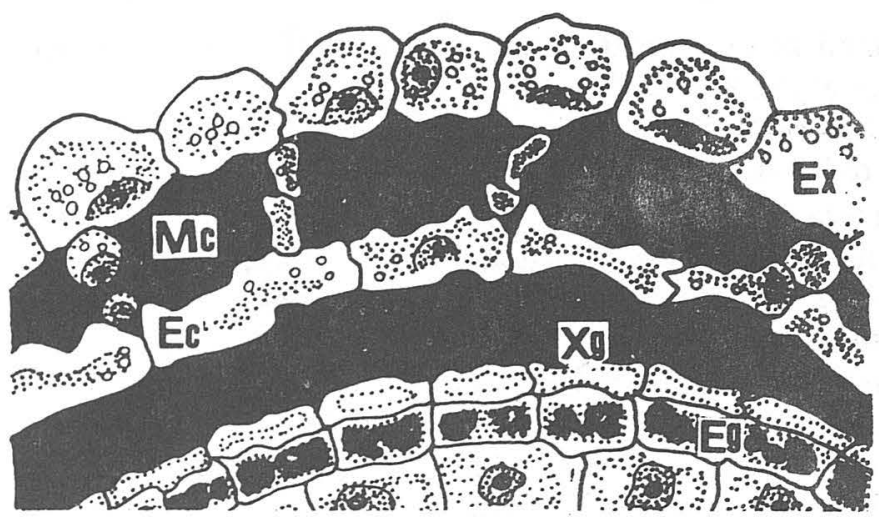

Fig. 20. Corte transversal del fruto joven. Cubierta de la semilla formada por exotegmen (Xg) sin taninos y endotegmen (Eg) con taninos abundantes. Las células de ambos estratos se aplastan y adoptan una forma tabular. Ec = endocarpo, Ex $=$ exocarpo, $\mathrm{Mc}=$ mesocarpo. Barra $=20 \mu \mathrm{m}$.

Durante el desarrollo de la semilla las células del exotegmen y endotegmen se extienden en el sentido tangencial y adoptan una forma tabular. El lumen de las células del endotegmen se llena con taninos, los cuales se observan como esferas refringentes pardas y rojas con tinción de safranina-verde fijo (fig. 20). El exotegmen finalmente se aplasta y desde la etapa de embrión globular avanzado, la semilla joven está cubierta solamente por el endotegmen (figs. 10, 14, 17, 21). En la semilla adulta el endotegmen se reduce hasta un grosor de $3 \mu \mathrm{m}$ y sus paredes desarrollan engrosamientos semejantes a finas estrías que tiñen de rojo con safranina. Al MEB estas estrías se ven paralelas, anastomosadas y orientadas sesgadamente en uno o dos sentidos, sobre la pared periclinal interna (fig. 16). Las paredes anticlinales son plegadas sobre sí mismas

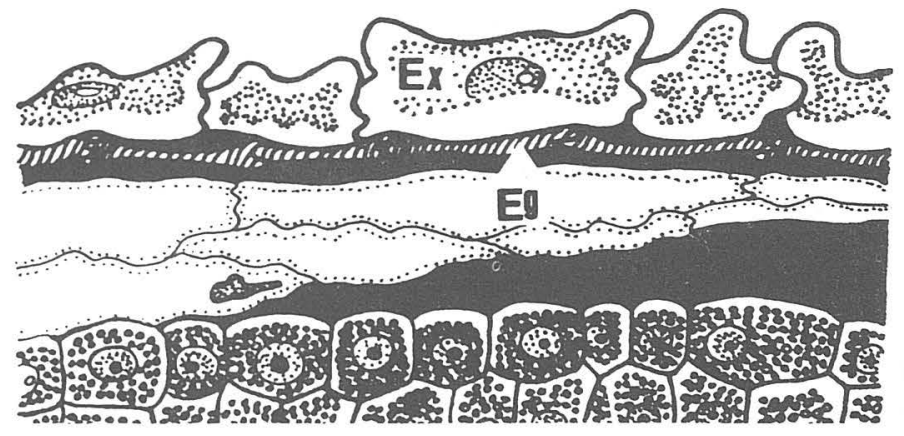

Fig. 21. Corte transversal del fruto maduro, pero no seco. El exocarpo (Ex) queda adherido al endotegmen (Eg). Las papilas se han colapsado, lo mismo que las células del endotegmen. Las paredes de las células del endotegmen muestran finas estrías. Barra $=20 \mu \mathrm{m}$. 
debido al aplastamiento, y se abultan donde se unen a la periclinal externa; la superficie de cada célula es algo cóncava (fig. 21).

Cutícula nucelar y calazal. En la semilla madura la cutícula más notoria es la nucelar, la cual rodea el saco embrionario. Con rojo $\mathrm{O}$ de aceite, esta cutícula se define como una línea roja de $5 \mu \mathrm{m}$ de grosor (figs. 24, 25). Por otro lado, en la zona calazal una cutícula gruesa en red tridimensional rodea las células en sus aristas y hace contacto con la cutícula nucelar (figs. 22,23,24). Además, estas células tienen cutícula delgada sobre sus caras. Las células involucradas en la red calazal son taniníferas.

Algunas extensiones de la red penetran entre las células amilíferas del perispermo. La cutícula nucelar, aislada y teñida con rojo $\mathrm{O}$ de aceite, presenta el aspecto de una bolsa roja. En su parte central, en la zona de la cálaza, se observa una red tridimensional con mallas de tamaño no uniforme (fig. 22). Esta cutícula calazal, de forma elíptica, mide 600 $\mu \mathrm{m}$ de largo, $150 \mu \mathrm{m}$ en su parte media y $80 \mu \mathrm{m}$ de ancho en sus extremos.

La cálaza y el tejido vascular. Aunque por definición la cálaza carece de límites precisos, en la semilla del huauzontle tiene forma semejante a un cono truncado (fig. 5) de base elíptica, cuyo diámetro mayor es perpendicular al plano mediano de la semilla. Para estimar los límites de la cálaza, nos fueron de gran ayuda dos características estructurales: a) la presencia de células ricas en taninos y b) las cutículas nucelar y calazal. En el óvulo y la semilla joven las células de la cálaza tienen vacuola

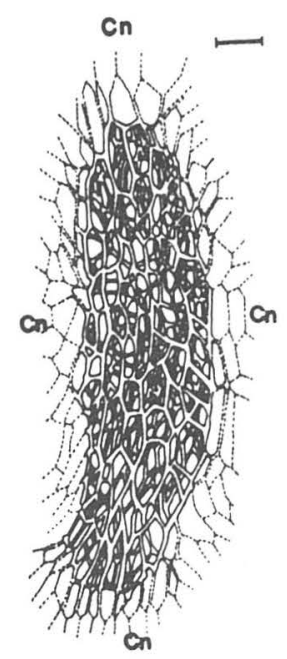

Fig. 22. Cutícula calazal entera formada por una red tridimensional elíptica rodeada por la cutícula nucelar $(\mathrm{Cn})$. Las líneas punteadas dobles son engrosamientos de las aristas de células nucelares que quedan por debajo de la cutícula nucelar. Las paredes anticlinales de la nucela dejan huellas en la cut́cula nucelar (líneas punteadas sencillas). Barra $=60 \mu \mathrm{m}$. 


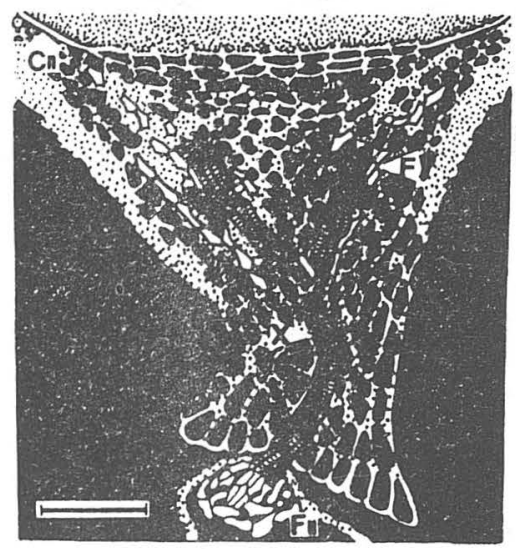

Fig. 23. Tejido vascular en semilla madura, pero no seca, en corte transmediano. Note como un haz penetra la cálaza a partir del funículo (Fu), el xilema se bifurca, y el floema rodea el xilema. $\mathrm{Cn}=$ cutícula nucelar, cutícula calazal (red en blanco). $\mathrm{F}=$ elemento criboso, $\mathrm{X}=$ elemento traqueal. Baria $=60 \mu \mathrm{m}$.

grande, almidón y núcleo notorio. Al madurar la semilla el almidón disminuye y algunas células de la cálaza se llenan con taninos (fig. 12). En la semilla adulta las células de la cálaza más cercanas al haz vascular, se caracterizan por contener grandes cuerpos tánicos que llenan completamente su lumen (fig. 23).

El tejido vascular en forma de un haz colateral penetra por el funículo y llega

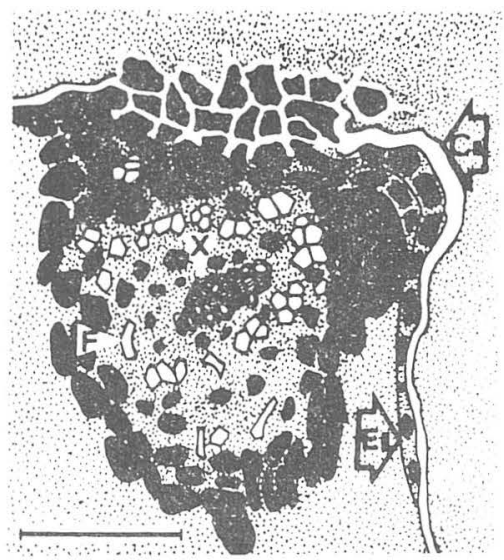

Fig. 24. Corte mediano de semilla madura, que muestra uno de los haces concéntricos. Cutícula calazal (red en blanco). $\mathrm{Cn}=$ cutícula nucelar, $\mathrm{Eg}=$ endotegmen, $\mathrm{F}=$ elemento criboso, $\mathrm{Fu}=$ funículo, $\mathrm{X}=$ elemento traqueal. Barra $=20 \mu \mathrm{m}$. 


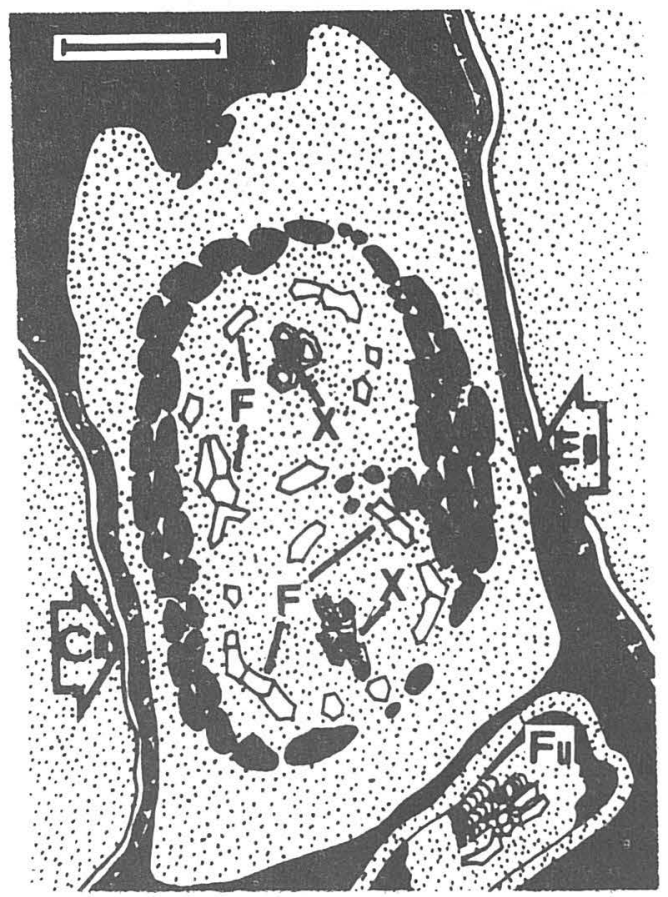

Fig. 25. Corte transversal de la cálaza. Observe el par de haces concéntricos hacia los extremos de la elipse. $\mathrm{Cn}=$ cutícula nucelar, $\mathrm{Eg}=$ endotegmen, $\mathrm{F}=$ elemento criboso, $\mathrm{Fu}=$ funículo, $\mathrm{X}=$ elemento traqueal. Barra $=60 \mu \mathrm{m}$.

hasta la cálaza. Cerca de la zona hilar el xilema está dirigido hacia el lado del micrópilo. $\mathrm{Al}$ aproximarse a la nucela, el haz de xilema se bifurca (fig. 23) y el floema se ramifica y rodea el xilema, por lo que se constituyen dos haces de tipo concéntrico (fig. 24), cuyos extremos se extienden hacia los extremos de la red de cutícula calazal (fig. 25).

\section{DISCUSIÓN}

El tegumento externo. El tegumento externo es persistente y cubre la semilla madura en casi todos los informes revisados de Caryophyllales: Phytolaccaceae (Mauritzon, 1934), Cactaceae (Engleman, 1960; Flores-Vindas y Engleman, 1976), Amaranthaceae (Kowal, 1954; Suárez-Ramos y Engleman, 1980), Caryophyllaceae (Buell, 1952), Chenopodiaceae (Artschwager, 1927; Williams, 1932; Artschwager y Starrett, 1933; Bhargava, 1936; Mahabale y Solansky, 1954a, 1954b). 
La reducción en el grosor de la cubierta de las semillas de Chenopodium berlandieri y la disminución en el número de estratos que la forman, han sucedido durante su domesticación (Wilson, 1981; Smith, 1984, 1989). Sin embargo, en el huauzontle aquí estudiado (Chenopodium berlandieri spp. nuttalliae), la reducción en extensión del tegumento externo y su crecimiento inverso, son fenómenos aparentemente excepcionales. Solamente podemos interpretar esto como una o más mutaciones fijadas por selección bajo domesticación. Hasta donde sabemos, estos fenómenos no han sido consignados en algún otro quenopodio, ni cultivado ni silvestre. La reducción extrema de la extensión del tegumento externo, posiblemente se pueda explicar: a) como una característica que refleja su alto grado de evolución bajo domesticación, b) como producto de una tasa de crecimiento reducida del tegumento externo y c) como un aborto del tegumento externo.

Flores-Vindas y Engleman (1976, cactáceas) y Suárez-Ramos y Engleman (1980, Amaranthus)indican que el color de las semillas negras probablemente es producido por los taninos incrustados en las paredes de la exotesta. Guinet (1959) señala que las semillas de C. berlandieri arvense son negras. En la semilla madura del huauzontle aquí estudiado, el tegumento externo reducido también es obscuro. En cortes las células de la exotesta se ven con gran cantidad de taninos, tanto en la pared periclinal externa como en el lumen celular. Los cambios durante la maduración de la exotesta del huauzontle, coinciden en varias maneras con lo descrito para Amaranthus hypochondriacus (Suárez-Ramos y Engleman, 1980), Chenopodium album (Bhargava, 1936), C. ambrosioides y C. murale (Mahabale y Solansky, 1954a, 1954b).

Las divisiones periclinales de la exotesta del huauzontle son comparables a la multiplicación en Nyctocereus serpentinus, cuya exotesta alcanza 23 estratos de células (Flores-Vindas y Engleman. 1976).

El tegumento interno. La semilla adulta del huauzontle está cubierta solamente por el endotegmen, ya que durante el desarrollo el exotegmen se aplasta, lo cual es aparentemente común en las semillas de Caryophyllales (Corner, 1976). En el huauzontle el exotegmen desaparece temprano y deja descubierto el endotegmen desde la etapa de embrión globular avanzado. La mayoría de las semillas de huauzontle aquí estudiadas presentó color pajizo, lo cual coincide con lo reportado por Wilson (1981). El aspecto finamente alveolado (visto por MEB) de la superficie del endotegmen del huauzontle, se debe a que las paredes periclinales externas se hunden hacia el lumen. Sobre la pared periclinal interna del endotegmen se obervaron engrosamientos semejantes a finas estrías, las cuales son típicas de muchas Caryophyllales (Netolitzky, 1926; Artschwager y Starrett, 1933; Kowal, 1954; Mahabale y Solansky, 1954a, 1954b; Engleman, 1960; Corner, 1976; Flores-Vindas y Engleman, 1976: Suárez-Ramos y Engleman, 1980). Es posible que la gran cantidad de taninos en el endotegmen, junto con la cutícula nucelar, protejan contra el ataque 
por patógenos y la desecación. Opinamos que los engrosamientos podrían proporcionar resistencia al estiramiento durante la expansión de la semilla joven.

Artschwager (1927), Artschwager y Starret (1933) y Suárez-Ramos y Engleman (1980) señalan la presencia de almidón en las células del tegumento externo y del tegumento interno de Beta y Amaranthus hypochondriacus, respectivamente, el cual desaparece al llenarse los lúmenes con taninos. Con APS se observó esto mismo en las células de la cálaza del huauzontle.

La cutícula calazal. La cutícula calazal del huauzontle está claramente limitada, al igual que en Beta (Netolitzky, 1926; Bennett y Esau, 1936) y cubre tanto las aristas como las caras de las células de esta región. Por esta razón el perispermo de la semilia de huauzontle queda totalmente aislado de los tejidos externos, como aparentemente ocurre en la semilla de la remolacha (Bennett y Esau, 1936). En Beta, Netolitzky (1926) consigna que los engrosamientos de las paredes de la placa calazal son de tipo colenquimático. Bennett y Esau (1936) comprobaron que tales engrosamientos son de naturaleza grasa, pero no los describieron como cutícula. Nosotros encontramos que tanto la cutícula nucelar como la calazal resistieron la hidrólisis y la oxidación y reaccionaron positivamente a la presencia de substancias lipoideas con rojo $\mathrm{O}$ de aceite. En cortes la cutícula calazal presenta un aspecto semejante al colénquima angular.

La cálaza y el tejido vascular. La disposición del tejido vascular de la semilla del huauzontle es muy semejante a la de Beta vulgaris (Bennett y Esau, 1936), aunque las ramas anficribales en esta última especie se extienden más hacia los extremos de la cutícula calazal. Agarwal y Sinclair (1987) consideran que algunos virus, bacterias y hongos pueden infectar áreas calazales, disolverlas y llegar hasta el embrión a través del tejido vascular. Beckman y Mueller (1970) postulan que las sustancias fenólicas actúan como un mecanismo de defensa contra infecciones vasculares. Estos autores observaron que algunas sustancias fenólicas, presentes en células especializadas del parénquima xilemático de raíces de plátano, se difunden después de una infección por microorganismos. En el huauzontle es posible que los taninos de las células cercanas al tejido vascular de la cálaza, formen un mecanismo de defensa semejante.

En esta investigación destaca el descubrimiento de a) la reducción de la extensión del tegumento externo y b) su crecimiento inverso, no reportados en otros quenopodios.

Agradecimientos. La primiera autora agradece a la Preparatoria Agrícola de la Universidad Autónoma Chapingo, por concesión de tiempo pagado para realizar la maestría. Jorge Valdez Carrasco y Néstor Bautista Martínez del Centro de Entomología del Colegio de Postgraduados, nos apoyaron en el trabajo de microscopía electrónica de barrido, y en el suministro de material de una parcela de huauzontle cv Santa Elena Siete. 


\section{LITERATURA CITADA}

Aellen, P. y T. Just. 1943. Key and synopsis of the American species of the genus Chenopodium L. Amer. Midl. Nat. 30:47-67.

Agarwal, V.K. y J.B. Sinclair. 1987. Principles of seed pathology. CRC Press, Boca Raton, Florida. $2 \mathrm{~V}$.

Artschwager, E. 1927. Development of flowers and seed in the sugar beet. J. Agr. Res. $34(1): 1-25$.

Artschwager, E. y R.C. Starrett. 1933. The time factor in fertilization and embryo development in the sugar beet. J. Agr. Res. 47(11):823-843.

BECKMAN, C.H. y Mueller, W.C. 1970. Distribution of phenols in specialized cells of banana roots. Phytopathology 60:79-82.

BENNETT, C.W. y K. ESAU. 1936. Further studies on the relation of the curly top virus to plant tissues. J. Agr. Res. 53(8):595-620.

Bhargava, H.R. 1936. The life history of Chenopodium album. Proc. Indian Acad. Sci. B. 46:179-200.

BuelL, K.M. 1952. Developmental morphology in Dianthus. I. Structure of pistil and seed development. Amer. J. Bot. 39:194-210.

Corner, E.J.H. 1976. The seeds of dicotyledons. Cambridge, London. 2 v.

Engleman, E.M. 1960. Ovule and seed development in certain cacti. Amer. J. Bot. 47:460-467.

Fisher, D.B. 1968. Protein staining of ribboned epon sections for light microscopy. Histochemie 16:92-96.

FLores-VINDAS, E.M. y E.M. ENGLEMAN. 1976. Apuntes sobre anatomía y morfología de las semillas de cactáceas. I. Desarrollo y estructura. Rev. Biol. Trop. 24(2):199-227.

Guinet, P. 1959. Essai didentification des graines de chénopodes commensaux des cultures ou cultivés en France. J. Agr. Trop. Bot. Appl. 6:241-266.

Kowal, T. 1954. Cechy morfologiczne i anatomiczne nasion rodzaju Amaranthus L. oraz klucze do ich oznaczania. (Características morfológicas y anatómicas de las semillas del genero Amaranthus L. y claves para su determinación). Monogr. Bot. 2:162-193.

Mahabale, T.S. y I.N. Solansky. 1954a. Studies in Chenopodiaceae. IV. Embryology of Chenopodium ambrosioides. J. Univ. Bombay 22:31-42.

Mahabale, T.S. y I.N. Solansky. 1954b. Studies in Chenopodiaceae. V. Embryology of Chenopodium murale. J. Univ. Bombay 23:25-37.

Mauritzon, V.J. 1934. Ein Beitrag zur Embryologie der Phy tolaccaceen und Cactaceen. Bot. Notiser 3:110-135.

Netolitzky, F. 1926. Anatomie der AngiospermenSamen. Handbuch der Pflanzenanatomie. Band X. Borntraeger, Berlin. $364 \mathrm{p}$.

Smith, B.D. 1984. Chenopodium as a prehistoric domesticate in Eastern North America: evidence from Russell Cave, Alabama. Science 226:165-170.

Smith, B.D. 1989. Origins of agriculture in eastern North America. Science 246:1566-1571. SuÁrez-Ramos, G. y E.M. Engleman. 1980. Depósito de taninos en la testa de Amaranthus hypocondriacus L. (alegría). Agrociencia 42:35-50. 
BOLETÍN DE LA SOCIEDAD BOTÁNICA DE MÉXICO, Núm. 54, 1994

Williams, M.E. 1932. The development of the embryo of Kochia scoparia. Bull. Torrey Bot. Club 59:391-400.

Wilson, H.D. 1981. Domesticated Chenopodium of the Ozark Bluff Dwellers. Econ. Bot. 35(2):233-239.

WILSON, H.D. y C.B. HEISER. 1979. The origin and evolutionary relationships of "huauzontle" (Chenopodium nuttalliae Safford) domesticated chenopod of Mexico. Amer. J. Bot. 66:198-206. 